\title{
Safety of artemether-lumefantrine in pregnant women with malaria: results of a prospective cohort study in Zambia
}

\author{
Christine Manyando ${ }^{1 *+}$, Rhoda Mkandawire ${ }^{2 \dagger}$, Lwipa Puma ${ }^{3 \dagger}$, Moses Sinkala ${ }^{4 \dagger}$, Evans Mpabalwani ${ }^{5 \dagger}$, Eric Njunju ${ }^{1 \dagger}$, \\ Melba Gomes ${ }^{6 \dagger}$, Isabela Ribeiro ${ }^{6 \dagger}$, Verena Walter ${ }^{7 \dagger}$, Mailis Virtanen ${ }^{7 \dagger}$, Raymond Schlienger ${ }^{7 \dagger}$, Marc Cousin ${ }^{7 \dagger}$, \\ Miriam Chipimo ${ }^{8 \dagger}$, Frank M Sullivan ${ }^{9 \dagger}$
}

\begin{abstract}
Background: Safety data regarding exposure to artemisinin-based combination therapy in pregnancy are limited. This prospective cohort study conducted in Zambia evaluated the safety of artemether-lumefantrine (AL) in pregnant women with malaria.

Methods: Pregnant women attending antenatal clinics were assigned to groups based on the drug used to treat their most recent malaria episode (AL vs. sulphadoxine-pyrimethamine, SP). Safety was assessed using standard and pregnancy-specific parameters. Post-delivery follow-up was six weeks for mothers and 12 months for live births. Primary outcome was perinatal mortality (stillbirth or neonatal death within seven days after birth).

Results: Data from 1,001 pregnant women ( $A L n=495 ; S P n=506)$ and 933 newborns ( $A L n=466 ; S P n=467$ ) showed: perinatal mortality (AL 4.2\%; SP 5.0\%), comprised of early neonatal mortality (each group 2.3\%), stillbirths (AL 1.9\%; SP 2.7\%); preterm deliveries (AL 14.1\%; SP 17.4\% of foetuses); and gestational age-adjusted low birth weight (AL 9.0\%; SP 7.7\%). Infant birth defect incidence was 1.8\% AL and 1.6\% SP, excluding umbilical hernia. Abortions prior to antenatal care could not be determined: abortion occurred in $4.5 \%$ of women treated with $\mathrm{AL}$ during their first trimester; none were reported in the 133 women exposed to SP and/or quinine during their first trimester. Overall development (including neurological assessment) was similar in both groups.

Conclusions: These data suggest that exposure to AL in pregnancy, including first trimester, is not associated with particular safety risks in terms of perinatal mortality, malformations, or developmental impairment. However, more data are required on $\mathrm{AL}$ use during the first trimester.
\end{abstract}

\section{Background}

More than 30 million women become pregnant each year in malaria-endemic areas of sub-Saharan Africa [1]. Malaria during pregnancy causes adverse outcomes, including abortion, anaemia, and low infant birth weight, with the latter complication due to foetal growth restriction and preterm delivery $[2,3]$. An important preventative strategy in highly endemic areas is intermittent preventive treatment (IPT) with sulphadoxine-pyrimethamine (SP) [4], and as SP becomes less effective

\footnotetext{
* Correspondence: cmanyando@yahoo.com

+ Contributed equally

${ }^{1}$ Tropical Diseases Research Centre, Ndola, Zambia

Full list of author information is available at the end of the article
}

with increasing Plasmodium falciparum resistance [5], effective treatment during pregnancy becomes more important.

The World Health Organization (WHO) recommends artemisinin-based combination therapy (ACT) as firstline treatment of $P$. falciparum malaria [6]. These guidelines state that artemisinin derivatives should be used to treat uncomplicated falciparum malaria in the second and third trimesters of pregnancy [6,7], but that they should not be used in the first trimester unless they are the only treatment available [6,7], or if the patient's life is threatened, or if treatment with quinine plus clindamycin has failed [6]. The guidelines take into account the greater confidence regarding the safety of ACT 
exposure in the second and third trimesters [6-11], and the scarcity of data on first trimester exposure versus the risk of embryotoxicity or death $[7,12,13]$.

Artemether-lumefantrine (AL; Coartem ${ }^{\circ}$, Novartis Pharma AG) is currently the most widely used ACT for acute, uncomplicated $P$. falciparum malaria. Zambia was one of the first countries in Africa to replace SP with $\mathrm{AL}$ as first-line therapy for malaria treatment, which occurred in 2004 [14]. Here, the results of a Zambian multi-centre, prospective cohort study to evaluate the safety of AL used to treat symptomatic malaria in pregnancy are described.

\section{Methods}

\section{Study population}

The study was carried out in Zambia at four antenatal clinics in the districts of Choma, Ndola and Lusaka. Data were collected between October 2004 and July 2008. Pregnant women were eligible for inclusion if they had received AL or SP for the treatment of malaria. Diagnosis was clinically or parasitologically confirmed. SP was the standard anti-malarial treatment during pregnancy and also used for IPT. Pregnant women were assigned to exposure groups according to the treatment received for the "index episode", defined as the most recently treated malaria episode prior to study entry.

\section{Study objectives and procedures}

The primary endpoint was the incidence of perinatal mortality (stillbirth or neonatal death within 7 days of birth). Secondary outcome measures were gestational age at delivery and birth weight adjusted for gestational age. In the absence of data on birth weight adjusted for gestational age from Zambia, the Zimbabwean birth weight data adjusted for gestational age as published by Munjanja \& Masona in 1990 [15] was used. A newborn was considered to have low birth weight if the observed birth weight was lower than the corresponding $5^{\text {th }}$ percentile of the Zimbabwean birth weight, according to gestational age in keeping with international standards. In addition, the following exploratory endpoints were assessed: frequency of spontaneous abortion, preterm delivery, neonatal mortality, maternal mortality, major and minor birth defects, and infant development.

Women attending the antenatal clinic were enrolled if they reported receiving treatment with either AL $(20 \mathrm{mg}$ artemether and $120 \mathrm{mg}$ lumefantrine) or SP (1500 mg sulphadoxine plus $75 \mathrm{mg}$ pyrimethamine) according to label recommendations. Exposure was verified by documentation from their outpatient (clinic) files, which also detailed diagnostic procedures performed, and dosage of any concomitant medication given. As per government policy, women received SP, at the same doses as described above, during the second or third trimester as
IPT. Treatment with any drug, including anti-malarials, prior to or after the index episode was recorded.

Women visited the antenatal clinic for assessment of safety parameters at baseline/enrolment, four weeks post-enrolment, four weeks pre-delivery, at delivery, and at six weeks post-delivery. Infants were followed up at six weeks, 14 weeks, and at 12 months after birth.

Safety assessments included monitoring and recording all adverse events (AEs) and serious adverse events (SAEs) up to six weeks after delivery. Pregnancy-specific assessments included rates of perinatal mortality defined as stillbirth (>28 weeks gestation) and early neonatal death (within seven days of birth), neonatal mortality ( $\leq 28$ days of birth), maternal mortality (up to six weeks post-delivery), spontaneous abortion ( $\leq 28$ weeks gestation), stillbirth, preterm delivery ( $\leq 37$ completed weeks), incidence of low birth weight, gestational age at delivery (estimated from the last menstrual period [LMP], or by a developmental score [Dubowitz assessment] [16], if the LMP was unknown), and incidence of major and minor birth defects. Concomitant infections were recorded. Minor/ major birth malformations were documented using a checklist. Neurodevelopmental assessment was performed at 14 weeks and 12 months after birth. The development of infants was assessed by the investigators either through a general assessment (e.g. smiling, lifting head, sitting unsupported, standing without assistance, crawling) or the Shoklo neurodevelopment assessment [17], or both.

This study was designed, implemented, and reported in accordance with ICH Good Clinical Practice, applicable local regulations, and the Declaration of Helsinki. The study protocol was approved by the local Ethics Review Committee of the Tropical Diseases Research Centre, Zambia, and WHO Ethics Review Committee, Geneva. All participants, or their parent/guardian (if the subject was a minor), gave written or finger-marked informed consent before study entry.

An independent Study Advisory Committee (SAC) reviewed unblinded data for 677 women and 392 infants on four occasions during the study and all data at the end of the study.

\section{Statistical analysis}

Perinatal mortality was summarized by exposure (AL or $\mathrm{SP})$ for the index malaria episode, together with traditional asymptotic as well as Pearson-Clopper one-sample two-sided 95\% confidence intervals (CI). No formal testing for statistical significance between the two exposure groups was performed; instead, 95\% CIs for the difference in proportions between the groups were constructed using traditional asymptotic methods and the Wilson score method without continuity correction. The odds ratio (with two-sided 95\% CI) was calculated for perinatal mortality. Women who discontinued the study 
prior to delivery, or who had a spontaneous abortion were not taken into account in the primary analysis. However, the robustness of the results was assessed by supportive analyses applying multiple missing data imputation techniques [18].

The propensity score technique assessing pre-defined baseline factors (five pregnancy-related and 10 diseaserelated factors) was used to mitigate the potential channelling effect due to non-random assignment of therapy [19]. With the targeted sample size of 500 patients in each group, a two-sided 95\% CI for precision on observed perinatal mortality (primary endpoint) would vary between $3 \%$ and $7 \%$ for an assumed background incidence of $5 \%$ in the Zambian population [20]. This precision of estimation was deemed satisfactory for a pilot study of this type. All data analyses were carried out according to a pre-established analysis plan.

\section{Results}

\section{Demographics and clinical characteristics}

A total of 1,001 pregnant women were enrolled, of whom $84.4 \%(845 / 1001)$ completed the study to six weeks after delivery (Figure 1). Demographic and clinical characteristics are shown in Table 1. Among the women

Figure 1: Participant flowchart

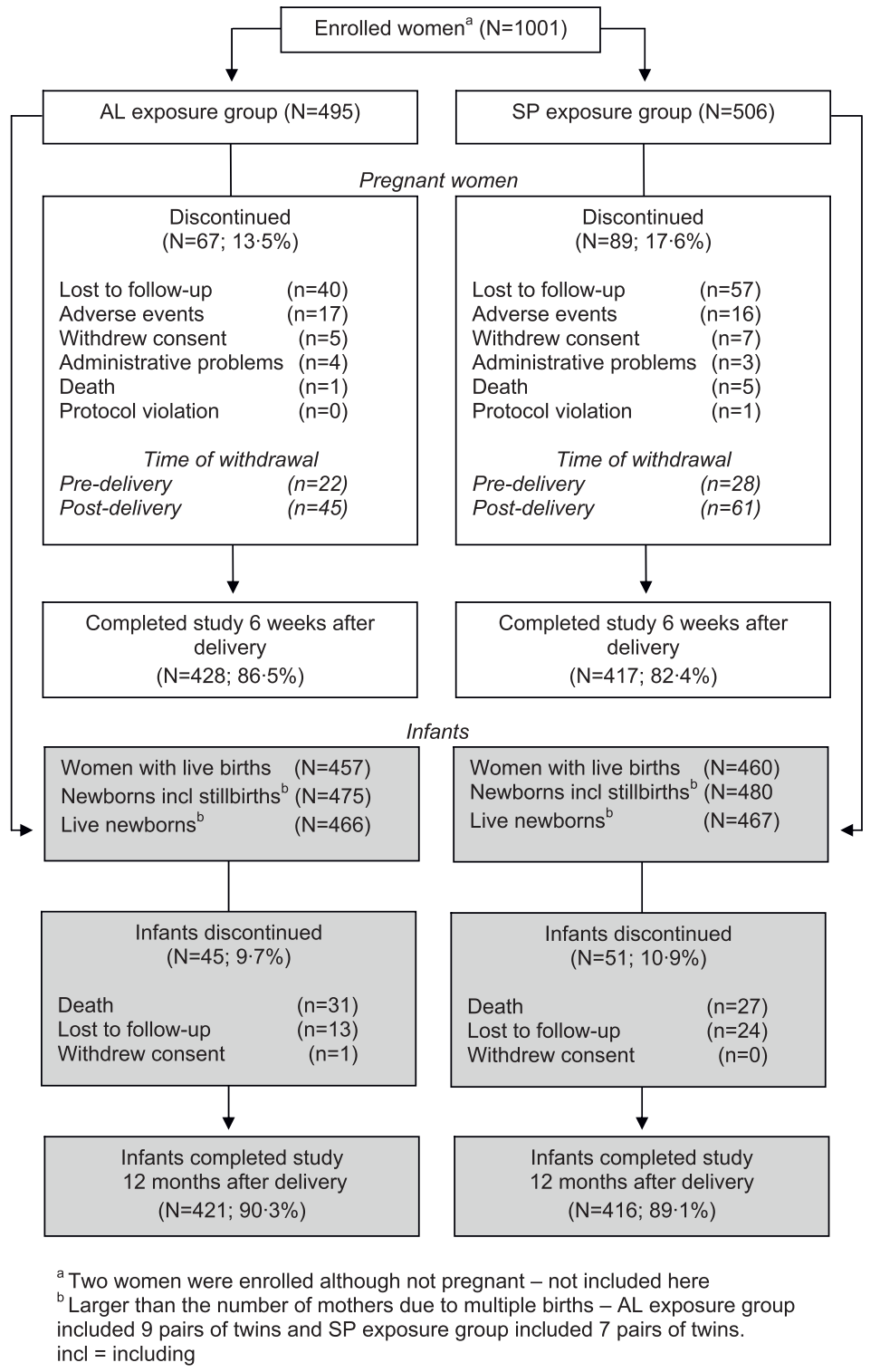

Figure 1 Participant flowchart. AL exposure group 9 pairs of twins; SP exposure group 7 pairs of twins. 
Table 1 Demographic and clinical characteristics of exposure groups at enrolment and anti-malarial treatment during current pregnancy

\begin{tabular}{|c|c|c|c|}
\hline & \multicolumn{2}{|c|}{ Exposure groups* } & \multirow{2}{*}{$\begin{array}{c}\text { Total } \\
(\mathrm{N}= \\
1001)\end{array}$} \\
\hline & $\begin{array}{l}\text { Artemether- } \\
\text { lumefantrine } \\
(\mathrm{N}=495)\end{array}$ & $\begin{array}{l}\text { Sulphadoxine- } \\
\text { pyrimethamine } \\
\quad(\mathrm{N}=506)\end{array}$ & \\
\hline \multicolumn{4}{|l|}{ Age - n (\%) } \\
\hline$<20$ years & $79(16.0)$ & $81(16.0)$ & $160(16.0)$ \\
\hline $20-24$ years & $167(33.7)$ & $151(29.8)$ & $318(31.8)$ \\
\hline $25-29$ years & $144(29.1)$ & $148(29.2)$ & $292(29.2)$ \\
\hline $30-39$ years & $101(20.4)$ & $119(23.5)$ & $220(22.0)$ \\
\hline$\geq 40$ years & $4(0.8)$ & $7(1.4)$ & $11(1.1)$ \\
\hline \multicolumn{4}{|l|}{ Time of index malaria episode relative to LMP - $\mathbf{n}(\%)$} \\
\hline Before LMP & $0(0)$ & $2(0.4)$ & $2(0.2)$ \\
\hline Date of LMP to 12 weeks & $145(29.3)$ & $115(22.7)$ & $260(26.0)$ \\
\hline$>12$ to 24 weeks & $169(34.1)$ & $205(40.5)$ & $374(37.4)$ \\
\hline$>24$ weeks & $162(32.7)$ & $161(31.8)$ & $323(32.3)$ \\
\hline LMP incomplete/unknown & $19(3.8)$ & $23(4.5)$ & $42(4.2)$ \\
\hline \multicolumn{4}{|c|}{$\begin{array}{l}\text { Treatment courses during first trimester including IPT with SP - n } \\
\text { (\%) }\end{array}$} \\
\hline Only AL & $142(28.7)$ & $5(1.0)$ & $147(14.7)$ \\
\hline Only SP & $7(1.4)$ & $120(23.7)$ & $127(12.7)$ \\
\hline $\mathrm{AL}$ and $\mathrm{SP}$ & $8(1.6)$ & $1(0.2)$ & $9(0.9)$ \\
\hline SP plus quinine & $0(0)$ & $2(0.4)$ & $2(0.2)$ \\
\hline Only quinine & $2(0.4)$ & $2(0.4)$ & $4(0.4)$ \\
\hline None (including unknown LMP date) & $336(67.9)$ & $376(74.3)$ & $712(71.1)$ \\
\hline Treatment received during current pregnancy ${ }^{* *} \mathrm{n}(\%)$ & $(\mathrm{N}=473)$ & $(\mathrm{N}=478)$ & $(\mathrm{N}=951$ \\
\hline Only AL or SP & $51(10.8)$ & $449(93.9)$ & $500(52.6)$ \\
\hline Both $\mathrm{AL}$ and $\mathrm{SP}$ & $412(87.1)$ & $13(2.7)$ & $425(44.7)$ \\
\hline $\mathrm{AL}$ or SP plus quinine & $1(0.2)$ & $13(2.7)$ & $14(1.5)$ \\
\hline Both $\mathrm{AL}$ and SP plus quinine & $9(1.9)$ & $3(0.6)$ & $12(1.3)$ \\
\hline Alcohol status (current) & $(\mathrm{N}=495)$ & $(\mathrm{N}=506)$ & $\begin{array}{c}(\mathrm{N}= \\
1001)\end{array}$ \\
\hline Non-drinker & $441(89.1)$ & $437(86.4)$ & $878(87.7)$ \\
\hline Drinker & $14(2.8)$ & $17(3.4)$ & $31(3.1)$ \\
\hline Unknown & $40(8.1)$ & $52(10.3)$ & $92(9.2)$ \\
\hline \multicolumn{4}{|l|}{ Alcohol intake frequency } \\
\hline Low & $11(2.2)$ & $11(2.2)$ & $22(2.2)$ \\
\hline Medium & $3(0.6)$ & $5(1.0)$ & $8(0.8)$ \\
\hline High & 0 & $1(0.2)$ & $1(0.1)$ \\
\hline \multicolumn{4}{|l|}{ Tobacco smoking history (current) } \\
\hline Non-smoker & $455(91.9)$ & $454(89.7)$ & $909(90.8)$ \\
\hline Smoker & 0 & 0 & 0 \\
\hline Unknown & $40(8.1)$ & $52(10.3)$ & $92(9.2)$ \\
\hline
\end{tabular}

Enrolled population: pregnant women who gave informed consent.

*Exposure groups represent the treatment given to the pregnant woman for the falciparum malaria episode that had occurred most recently prior to enrolment (index episode).

** Data from women with known delivery status.

$\mathrm{AL}=$ artemether-lumefantrine

IPT = intermittent preventive treatment (with SP)

LMP = last menstrual period

$\mathrm{SP}=$ sulphadoxine-pyrimethamine 
enrolled, 98.9\% had received at least some degree of schooling at the primary level and $52.2 \%$ had received some degree of secondary education.

The index episode was predominantly diagnosed based on symptoms: malaria was unconfirmed in $82.0 \%$ of the $\mathrm{AL}$ and $87.2 \%$ of the SP exposure groups. Details of anti-malarial treatment received during the current pregnancy are shown in Table 1. The majority of women with known delivery status in the AL group (412/473; 87.1\%) had received both AL and SP (as IPT) during the current pregnancy. Conversely, most women in the SP group had received only SP for treatment $(449 / 478 ; 93.9 \%)$ and IPT prophylaxis in the $2^{\text {nd }}$ and $3^{\text {rd }}$ trimesters, in accordance with National Health policy in Zambia; a single dose of $1500 \mathrm{mg}$ of sulphadoxine plus $75 \mathrm{mg}$ pyrimethamine was used for treatment or prophylaxis. In total, $2.7 \%(13 / 478)$ of women in the SP group were exposed to both AL and SP. Most women received two to four courses of anti-malarial treatment during the pregnancy, including IPT. A small proportion of women in each group (AL 2.1\%; SP 3.3\%) were also exposed to quinine. Approximately $70 \%$ of enrolled women had taken their first anti-malarial treatment 12 weeks after their LMP. In total, 156 women (150/495 [30.3\%] from the AL group, plus 6 from the SP group) received $\mathrm{AL}$ treatment during the first trimester, while 138 women (123/506 [24.3\%] from the SP group, plus 15 from the AL group) received SP treatment during the first trimester.

All patients reported taking the full prescribed course of anti-malarial treatment, and very few $(<0.4 \%)$ reported vomiting the medication. More than $95 \%$ of all enrolled women received at least one concomitant medication (other than anti-malarial therapy), most commonly folic acid and oral iron preparations. All women were counselled for HIV testing. Approximately $30 \%$ of women in the AL group and $38 \%$ in the SP exposure group were tested for HIV: overall, $22 \%$ of women with a test result were reported as HIVpositive.

\section{Pregnancy outcomes}

A summary of pregnancy outcomes is shown in Table 2 . Overall perinatal mortality was similar for both exposure groups (Table 3) (AL 4.2\% [asymptotic 95\% CI 2.4 6.0]; SP 5.0\% [asymptotic 95\% CI 3.1 - 6.9]; odds ratio [AL versus SP] 0.84 [asymptotic 95\% CI 0.45 - 1.53]). First trimester perinatal mortality is reported in detail below. Subgroup analyses on perinatal mortality did not show any significant between-group differences.

Perinatal mortality status was missing for $6.2 \%$ of women due to abortion (1.2\%) or withdrawal prior to delivery (5.0\%). However, multiple imputation analyses demonstrated that the results were robust with respect to missing data.

Women treated with AL for the index episode had a higher frequency of confirmed malaria in comparison with women treated with SP. An analysis to correct for any possible channelling bias showed no effect on perinatal mortality due to more AL patients having confirmed malaria (adjusted odds ratio of 0.79 [95\% Wald CI 0.43 - 1.46] versus the observed unadjusted odds ratio of 0.84 [asymptotic $95 \%$ CI $0.45-1.53$ ]).

Stillbirths occurred in $1.9 \%$ of the AL group and in $2.7 \%$ of the SP group. Of the nine mothers who had stillbirths in the AL group, AL was the last exposure in three cases; eight women had been exposed to SP for IPT, six were exposed after the AL-treated index episode, and two before it. Thirteen women in the SP group had stillbirths: in five cases, SP was the last exposure (as treatment for the index episode); six of the thirteen women had IPT; and two women were treated with quinine for additional episodes of malaria.

Early neonatal death was similar for each exposure group (2.3\% for each group). In the AL group, four of the 11 neonatal deaths occurred after delivery at home. All 11 neonatal deaths in the SP group occurred after delivery at a hospital or health centre.

There were seven cases of abortion in the AL group, all occurring in women who were exposed to AL during their first trimester (further details below); the last anti-

Table 2 Pregnancy outcome by exposure group

\begin{tabular}{lcc}
\hline Pregnancy outcome $-\mathbf{n}(\%)$ & $\begin{array}{c}\text { Artemether-lumefantrine } \\
(\mathbf{N}=\mathbf{5 0 4})\end{array}$ & $\begin{array}{c}\text { Sulphadoxine-pyrimethamine } \\
(\mathbf{N}=\mathbf{5 1 6})\end{array}$ \\
\hline Abortion ( $\leq 28$ weeks of gestation) & $7^{*}(1.4)$ & $8^{* *}(1.6)$ \\
Stillbirth (>28 weeks of gestation) & $9(1.8)$ & $13(2.5)$ \\
Preterm delivery (<37 completed weeks of gestation) & $71(14.1)$ & $90(17.4)$ \\
Full term delivery ( $\geq 37$ completed weeks of gestation) & $395(78.4)$ & $377(73.1)$ \\
Unknown (mother withdrawn prior to delivery) & $22(4.4)$ & $28(5.4)$ \\
\hline
\end{tabular}

Enrolled population: newborns, stillbirths, and aborted foetuses or pregnant women who were withdrawn prior to delivery.

${ }^{*}$ All first trimester exposures.

**5 abortions: one woman with triplets, one with twins - none had first trimester exposure.

One patient from the AL group had an ectopic pregnancy with laparotomy performed to remove the foetus. This patient has pregnancy outcome "unknown" as she was withdrawn due to an adverse event (ectopic pregnancy) prior to "delivery". 
Table 3 Perinatal mortality (stillbirths plus neonatal deaths) by exposure group

\begin{tabular}{lcc}
\hline & $\begin{array}{c}\text { Artemether-lumefantrine } \\
\text { (N = 475) }\end{array}$ & $\begin{array}{c}\text { Sulphadoxine-pyrimethamine } \\
\text { (N = 480) }\end{array}$ \\
\hline $\begin{array}{l}\text { Perinatal mortality (primary outcome) - } \mathbf{n} \\
\text { (\%) }\end{array}$ & $20(4.2)$ & $24(5.0)$ \\
\hline Asymptotic 95\% Cl & $2.4-6.0$ & $3.1-6.9$ \\
Pearson-Clopper 95\% Cl & $2.6-6.4$ & $3.2-7.3$ \\
Stillbirth - $\mathrm{n}$ (\%) & $9(1.9)$ & $13(2.7)$ \\
Neonatal death $\leq 7$ days after birth - n & $11(2.3)$ & $11(2.3)$ \\
(\%) & & \\
\hline
\end{tabular}

\begin{tabular}{|c|c|c|c|c|c|}
\hline & \multicolumn{5}{|c|}{ Exposure to anti-malarial agent(s) during first trimester* } \\
\hline & $\begin{array}{c}\text { AL only }(\mathrm{N}= \\
135)\end{array}$ & $\begin{array}{c}A L+\underset{7}{S P}(N= \\
\text { (N) }\end{array}$ & $\begin{array}{c}\text { SP or/and quinine }(\mathrm{N}= \\
129)\end{array}$ & $\begin{array}{l}\text { None }(\mathrm{N}= \\
644)\end{array}$ & $\begin{array}{l}\text { Unknown }(\mathrm{N}= \\
40)\end{array}$ \\
\hline Perinatal mortality - $\mathrm{n}(\%)$ & $6(4.4)$ & $1(14.3)$ & $5(3.9)$ & $31(4.8)$ & $1(2.5)$ \\
\hline Stillbirth (>28 weeks gestation) & $2(1.5)$ & $0(0)$ & $3(2.3)$ & $17(2.6)$ & $0(0)$ \\
\hline Death $\leq 7$ days after birth & $4(3.0)$ & $1(14.3)$ & $2(1.6)$ & $14(2.2)$ & $1(2.5)$ \\
\hline
\end{tabular}

Enrolled population: newborns and stillbirths.

Perinatal mortality: stillbirth or early neonatal death within 7 days after birth.

$\mathrm{AL}=$ artemether-lumefantrine; $\mathrm{Cl}$ = confidence interval; $\mathrm{SP}=$ sulphadoxine-pyrimethamine.

* Data from newborns and stillbirths with known delivery status.

malarial exposure was AL (index episode) in six cases, and in the remaining case SP was given for treatment of a malaria episode occurring after the index episode. Eight abortions occurred in five women in the SP group, all second or third trimester exposures (one was carrying triplets, another was carrying twins): the last antimalarial exposure was SP (index episode) in one case, SP (IPT) in three cases, and quinine (additional malaria episode) in the remaining case.

\section{Infant outcomes at birth}

Infant outcomes are summarized in Table 4. Low birth weight according to gestational age occurred in $9.0 \%$ of the AL and $7.7 \%$ of the SP group. Mean and median birth weights, head circumference, body length, and sex distribution were similar in both exposure groups. Mean and median gestational ages determined using LMP were comparable for the two groups (39.0 weeks each), as were the values calculated from the Dubowitz test (mean/median: AL group 37.6/37.7 weeks; SP group $38.2 / 38.1$ weeks).

Birth defects in infants were detected by midwives in $6.5 \%$ of the AL group and $4.1 \%$ of the SP group (Table $5)$. The between-group difference was largely due to a higher rate of umbilical hernia in the AL group (AL 4.7\%; SP 2.7\%). The majority of these had resolved by the 12 month evaluation (Table 6). Excluding umbilical hernia, which is a common reversible defect in African children [21,22], the infant birth defect frequency was $1.8 \%$ for AL and $1.6 \%$ for SP. There was no pattern of distribution of any birth defect in either exposure group. In the AL group, multiple birth defects were reported in two infants: one had trisomy 21 , the other had trisomy
18. Polydactyly was reported in seven infants and occurred in a similar proportion in each group (AL 0.7\%; SP 0.9\%).

Infant outcomes and developmental assessments from birth to 12 months

Mean and median height and weight were very similar in both groups at birth, 14 weeks, and at 12 months after delivery (data not shown). The general developmental assessment in 833 infants (427 AL; $406 \mathrm{SP}$ ) at 14

Table 4 Gestational age and weight of infants at birth by exposure group

\begin{tabular}{|c|c|c|}
\hline & $\begin{array}{l}\text { Artemether- } \\
\text { lumefantrine } \\
(\mathrm{N}=466)\end{array}$ & $\begin{array}{l}\text { Sulphadoxine- } \\
\text { pyrimethamine } \\
\quad(N=467)\end{array}$ \\
\hline \multicolumn{3}{|c|}{ Gestational age at delivery, determined by LMP } \\
\hline $\begin{array}{l}\text { Number of } \\
\text { observations }\end{array}$ & 448 & 445 \\
\hline Mean/Median weeks & $39.0 / 39.0$ & $38.9 / 39.0$ \\
\hline \multicolumn{3}{|l|}{ Distribution - n (\%) } \\
\hline$\leq 28$ weeks & $5(1.1)$ & $2(0.4)$ \\
\hline $\begin{array}{l}>28 \text { to }<37 \\
\text { weeks }\end{array}$ & $58(12.4)$ & $85(18.2)$ \\
\hline$\geq 37$ weeks & $385(82.6)$ & $358(76.7)$ \\
\hline Missing & $18(3.9)$ & $22(4.7)$ \\
\hline \multicolumn{3}{|l|}{ Birth weight - g } \\
\hline $\begin{array}{l}\text { Number of } \\
\text { observations }\end{array}$ & 448 & 444 \\
\hline Mean (SD) & $3058.3(515.96)$ & $3039.2(495.26)$ \\
\hline Median (Range) & $3000(900-4700)$ & $3000(1300-4500)$ \\
\hline
\end{tabular}

Enrolled population: newborn infants.

LMP = last menstrual period

Patients with a missing birth weight or a missing gestational age were not taken into account in this Table. 
Table 5 Birth defects reported from the time of delivery to 14 weeks by exposure group

\begin{tabular}{|c|c|c|}
\hline & $\begin{array}{c}\text { Artemether- } \\
\text { lumefantrine } \\
(N=466)\end{array}$ & $\begin{array}{l}\text { Sulphadoxine- } \\
\text { pyrimethamine } \\
(\mathrm{N}=467)\end{array}$ \\
\hline $\begin{array}{l}\text { Total number infants with } \\
\text { malformations } s^{a}-n(\%)\end{array}$ & $29 / 449^{b}(6.5)$ & $18 / 444^{\mathrm{b}}(4.1)$ \\
\hline \multicolumn{3}{|l|}{$\begin{array}{l}\text { Diagnosis of congenital } \\
\text { anomaly/birth defect }\end{array}$} \\
\hline Umbilical hernia & $21(4.7)$ & $12(2.7)$ \\
\hline Polydactyly & $3(0.7)$ & $4(0.9)$ \\
\hline Dermal cyst & $0(-)$ & $1(0.2)$ \\
\hline Ear malformation & $0(-)$ & $1(0.2)$ \\
\hline $\begin{array}{l}\text { Genitourinary system: small } \\
\text { labiac }^{c}\end{array}$ & $1(0.2)$ & $0(-)$ \\
\hline Hair: $\operatorname{lanugo}^{c}$ & $1(0.2)$ & $0(-)$ \\
\hline Inguinal hernia & $0(-)$ & $1(0.2)$ \\
\hline $\begin{array}{l}\text { Limbs: hyperextensibility of } \\
\text { joint }\end{array}$ & $1(0.2)$ & $0(-)$ \\
\hline Nose: small ${ }^{c}$ & $1(0.2)$ & $0(-)$ \\
\hline Skin hyperpigmentation & $1(0.2)$ & $0(-)$ \\
\hline Trisomy $18^{d}$ & $1(0.2)$ & $0(-)$ \\
\hline Trisomy $21^{\mathrm{e}}$ & $1(0.2)$ & $0(-)$ \\
\hline
\end{tabular}

Enrolled population: newborn infants.

No distinction was made between major and minor birth defects on the case report form.

${ }^{\mathrm{a}}$ Any malformation $=$ any finding other than normal or any diagnosis of congenital anomaly/birth defect reported.

${ }^{b}$ Number of newborn infants with assessment performed at least once at delivery, 6 weeks, or 14 weeks post-delivery. No assessments were available for 17 infants in the AL group and 23 in the SP group.

'Reported in the same patient.

${ }^{\mathrm{d}}$ Reported malformations: Ears - low set; Mouth - high arched palate; Cranium - microencephaly/anencephaly; Limbs - clenched with overlapping fingers. ${ }^{\mathrm{e}}$ Reported malformations: Ears - low set; Mouth - high arched palate; CVS murmur; Chest - short sternum; Cranium - low occiput; Eyes - upward slanting; Mouth - protruding tongue; Neck - short; Nose - low nasal bridge.

In the SP group, one child was reported to have had umbilical hernia and polydactyly.

weeks (smiling, lifting head) and at 12 months (sitting unsupported, standing without assistance, crawling) was also similar for each group, and virtually all infants met their expected developmental milestones. In addition, infants of mothers only exposed to AL or SP compared well with the overall group.

Data from the Shoklo neurodevelopmental evaluation, performed in 530 infants (298 AL; $232 \mathrm{SP}$ ), revealed very similar mean and median values for each exposure group. Tone and behaviour scores were similar at 14 weeks and 12 months, but motor milestone and coordination scores increased considerably over the study period. No differences in Shoklo neurodevelopment scores were observed in infants of mothers who had been exposed only to AL or to SP: more than $98 \%$ of infants assessed achieved a score of "good" or "excellent" at 14 weeks and at 12 months.

Neonatal mortality rate (death within 28 days of birth) was $3.0 \%$ in each group. In many cases the cause of death was unknown and the most common reported causes were prematurity and asphyxia.

\section{Exposure to anti-malarials in the first trimester (exploratory analyses)}

A total of 156 women (150/495 [30.3\%] from the AL plus 6 from the SP group) received AL treatment during the first trimester, primarily for treatment of the index episode (Table 1). Foetuses of women exposed to AL only during the first trimester had a similar rate of fullterm delivery to those who had no first trimester antimalarial exposure (AL alone: 75.3\% [113/150]; none: $76.5 \%$ [523/684]). The rate of preterm delivery was highest in foetuses of women exposed to SP and/or quinine during the first trimester (SP and/or quinine: 20.7\% [28/ 135]; AL alone 13.3\% [20/150]; none 15.2\% [104/684]) (Table 7).

A total of 159 foetuses were exposed to AL during the first trimester, either AL only $(n=150)$ or AL plus SP $(n=9)$ (Table 7). Six abortions occurred in this population (AL alone: 4 cases; AL plus SP: 2 cases) giving a rate of $3.8 \%$ (Table 8). One further abortion occurred in a woman who was likely to have taken AL during the first trimester (incomplete LMP date). Confounding factors were present in four cases; one had syphilis, two had multiple malarial episodes, and one received concomitant treatment with salbutamol and AL for a threatened abortion. In 135 foetuses exposed to SP and/or quinine during the first trimester, no abortions were reported.

Perinatal mortality was very similar whether first trimester exposure was to AL alone, or to SP and/or quinine, or if no anti-malarial therapy had been received (Table 3). Among women who received AL during the first trimester, $4.3 \%(6 / 140)$ newborns died within 28 days after birth compared with 3.0\% (19/627) among women who received no anti-malarials and $1.6 \%(2 / 126)$ among women who only received SP and/or quinine during the first trimester.

Birth weight (adjusted for gestational age or not) showed no notable differences between the groups.

The incidence of malformations in babies born to mothers who received AL only in the first trimester was $6.9 \%$ (9/130); eight of these nine cases were umbilical hernias, and the remaining baby was reported as having small genital labia, lanugo, and a small nose (Table 6). The malformation rate in infants from women exposed to other anti-malarial agents was $6.6 \%(8 / 121)$, and $4.5 \%$ $(27 / 596)$ in those with no anti-malarial exposure in the first trimester.

The Shoklo neurodevelopmental assessment of infants born to women exposed to $\mathrm{AL}$ in the first trimester were very similar to results for SP: $98.8 \%(83 / 84)$ of infants from the AL group achieved a score of "good" or 
Table 6 Birth defects reported from time of delivery until 14 weeks after birth, according to anti-malarial drug exposure during the first trimester

\begin{tabular}{|c|c|c|c|c|c|}
\hline & \multicolumn{5}{|c|}{ Exposure to anti-malarial(s) during first trimester } \\
\hline & $\begin{array}{l}\text { AL only } \\
(\mathrm{N}=133)\end{array}$ & $\begin{array}{l}\text { AL plus SP } \\
(\mathrm{N}=7)\end{array}$ & $\begin{array}{l}\text { SP or/and quinine } \\
(\mathrm{N}=126)\end{array}$ & $\begin{array}{l}\text { None } \\
(N=627)\end{array}$ & $\begin{array}{l}\text { Unknown } \\
(\mathrm{N}=40)\end{array}$ \\
\hline Total number of infants with malformations (\%) & $9 / 130(6.9)$ & $0 / 7(-)$ & $8 / 121(6.6)$ & $27 / 596(4.5)$ & $3 / 39(7.7)$ \\
\hline Umbilical hernia ${ }^{4}$ & $8(6.2)$ & $0(-)$ & $5(4.1)$ & $20(3.4)$ & $0(-)$ \\
\hline Polydactyly & $0(-)$ & $0(-)$ & $1(0.8)$ & $4(0.7)$ & $2(5.1)$ \\
\hline Dermal cyst & $0(-)$ & $0(-)$ & $1(0.8)$ & $0(-)$ & $0(-)$ \\
\hline Ear malformation & $0(-)$ & $0(-)$ & $1(0.8)$ & $0(-)$ & $0(-)$ \\
\hline Genitourinary system: small labia ${ }^{1}$ & $1(0.8)$ & $0(-)$ & $0(-)$ & $0(-)$ & $0(-)$ \\
\hline Hair: lanugo ${ }^{1}$ & $1(0.8)$ & $0(-)$ & $0(-)$ & $0(-)$ & $0(-)$ \\
\hline Inguinal hernia & $0(-)$ & $0(-)$ & $0(-)$ & $1(0.2)$ & $0(-)$ \\
\hline Limbs: hyperextensibility of joint & $0(-)$ & $0(-)$ & $0(-)$ & $0(-)$ & $1(2.6)$ \\
\hline Nose: small ${ }^{1}$ & $1(0.8)$ & $0(-)$ & $0(-)$ & $0(-)$ & $0(-)$ \\
\hline Skin hyperpigmentation & $0(-)$ & $0(-)$ & $0(-)$ & $1(0.2)$ & $0(-)$ \\
\hline Trisomy $18^{2}$ & $0(-)$ & $0(-)$ & $0(-)$ & $1(0.2)$ & $0(-)$ \\
\hline Trisomy $21^{3}$ & $0(-)$ & $0(-)$ & $0(-)$ & $1(0.2)$ & $0(-)$ \\
\hline
\end{tabular}

Enrolled population: newborns.

${ }^{1}$ All of these malformations were reported in the same patient.

${ }^{2}$ Reported malformations in this patient: Ears - low set; Mouth - high arched palate; Cranium microencephaly/anencephaly; Limbs - clenched with overlapping fingers.

${ }^{3}$ Reported malformations in this patient: Ears - low set; Mouth - high arched palate; CVS murmur; Chest - short sternum; Cranium: flat occiput; Eyes - upward slanting; Mouth: protruding tongue; Neck - short; Nose - low nasal bridge.

${ }^{4}$ No umbilical hernia was detected at birth. Of 21 cases reported in the AL exposure group, 12 detected at week 6 were resolved by week 14 . All remaining umbilical hernias had resolved by 12 months except for one infant who died prior to 12 months from a febrile illness. The mother of one infant with an umbilical hernia had received quinine during the first trimester of pregnancy, before AL treatment of the index episode (not in the first trimester) and another had received SP during the first trimester. In eight additional cases, the mother had received AL treatment in the first trimester, in each case to treat the index episode of malaria. In the SP group, among 12 infants with umbilical hernias, 7 had resolved by week 14, the remainder by month 12 , with the exception of 1 case lost to follow-up, and one infant who died from pneumonia.

"excellent" at 14 weeks, and 100\% (78/78) achieved the same scores at 12 months.

\section{General safety outcomes}

A summary of common AEs is presented in Table 9. The two groups were generally similar in their observed AE profiles, the most notable differences being the rates of premature delivery and of malaria as an AE, both of which were higher in the SP group. SAEs, most commonly complications of pregnancy and infections, occurred in $6.5 \%$ of women in the AL group and in $7.3 \%$ of those exposed to SP.

There were six maternal deaths during the study; one death $(0.2 \%)$ in the AL group (anaemia secondary to spontaneous abortion), and five deaths (1.0\%) in the SP group (one from Kaposi's sarcoma, three from infections [pneumonia, sepsis, and viral encephalitis], and one from "undiagnosed illness"). Mean haemoglobin levels 4 weeks after enrolment and at delivery were 12.0 and $11.6 \mathrm{~g} / \mathrm{dL}$ in the AL group, and 11.9 and $11.7 \mathrm{~g} / \mathrm{dL}$ in the SP group, respectively.

Table 7 Pregnancy outcome by exposure group, according to anti-malarial drug exposure during the first trimester

\begin{tabular}{|c|c|c|c|c|c|}
\hline & \multicolumn{5}{|c|}{ Exposure to anti-malarial(s) during first trimester } \\
\hline & $\begin{array}{c}\text { AL only } \\
(N=150)\end{array}$ & $\begin{array}{l}\text { AL plus SP } \\
(\mathrm{N}=9)\end{array}$ & $\begin{array}{l}\text { SP or/and quinine } \\
(\mathrm{N}=135)\end{array}$ & $\begin{array}{c}\text { None } \\
(\mathrm{N}=684)\end{array}$ & $\begin{array}{c}\text { Unknown } \\
(\mathrm{N}=42)\end{array}$ \\
\hline \multicolumn{6}{|l|}{ Pregnancy outcome - n (\%) } \\
\hline Abortion ( $\leq 28$ weeks) & $4(2.7)$ & $2(22.2)$ & $0(-)$ & $8^{*}(1.2)$ & $1^{* *}(2.4)$ \\
\hline Stillbirth ( $>28$ weeks) & $2(1.3)$ & $0(-)$ & $3(2.2)$ & $17(2.5)$ & $0(-)$ \\
\hline Preterm delivery (<37 weeks) & $20(13.3)$ & $1(11.1)$ & $28(20.7)$ & $104(15.2)$ & $8(19.0)$ \\
\hline Full term delivery ( $\geq 37$ weeks) & $113(75.3)$ & $6(66.7)$ & $98(72.6)$ & $523(76.5)$ & $32(76.2)$ \\
\hline Unknown (mother withdrawn prior to delivery) & $11(7.3)$ & $0(-)$ & $6(4.4)$ & $32(4.7)$ & $1(2.4)$ \\
\hline
\end{tabular}

Enrolled population: newborns, stillbirths and aborted foetuses

$\mathrm{AL}=$ artemether-lumefantrine; $\mathrm{SP}=$ sulphadoxine-pyrimethamine

*5 abortions: one woman with triplets, one with twins

** Incomplete date of last menstrual period, therefore, counted as unknown first trimester exposure (a woman who was likely to have taken AL during the first trimester) 
Table 8 Abortion occurring in women treated with artemether-lumefantrine

\begin{tabular}{|c|c|c|c|c|}
\hline Case & $\begin{array}{l}\text { Time of abortion } \\
\text { (gestation week) }\end{array}$ & $\begin{array}{c}\text { Time of AL } \\
\text { treatment (gestation } \\
\text { week) }\end{array}$ & $\begin{array}{l}\text { Reason for } \\
A L \text { treatment }\end{array}$ & Comments \\
\hline A & 13 & 9 & Index episode & Syphilis at Week 10 \\
\hline B & 10 & 6 & Index episode & - \\
\hline C & 18 & 6 & Index episode & - \\
\hline $\mathrm{D}$ & 15 & 7 & Index episode & Viable embryo at Week 11 on ultrasound \\
\hline $\mathrm{E}$ & $27^{\mathrm{a}}$ & 6 and 16 & Index episode & 3 malaria episodes at Weeks 6, 11 (received SP), and 16 \\
\hline $\mathrm{F}$ & 22 & 10 & $\begin{array}{l}\text { Non-index } \\
\text { episode }\end{array}$ & $\begin{array}{l}2 \text { previous spontaneous abortions; } 3 \text { malaria episodes at Weeks } 7 \text { (received SP), } \\
10 \text {, and } 22 \text { (received SP); at Week } 20 \text { severe respiratory tract infection, anaemia, } \\
\text { oral candidiasis, and immunosuppression (suspected HIV positive): spontaneous } \\
\text { abortion at Week 22, followed by maternal death } 24 \text { hours later }\end{array}$ \\
\hline$G^{b}$ & $\begin{array}{l}6 \text { days after } A L \\
\text { treatment }\end{array}$ & $\begin{array}{c}\text { Between Weeks } 6 \text { and } \\
9\end{array}$ & Index episode & Treatment with salbutamol for threatened abortion during AL treatment \\
\hline
\end{tabular}

All cases of abortion occurred in women who received AL during the first trimester; cases $A-D$, and G received AL only during the pregnancy. Index episode: falciparum malaria episode that had occurred most recently prior to study enrolment.

$\mathrm{AL}=$ artemether-lumefantrine; $\mathrm{SP}=$ sulphadoxine-pyrimethamine

a Therapeutic abortion following intrauterine death.

${ }^{\mathrm{b}}$ Incomplete LMP date, therefore, counted as unknown first trimester exposure.

The incidence of non-fatal SAEs was similar (AL 21.8\% [108/495] vs. SP $23.3 \%$ [118/506]). The most frequent non-fatal SAEs were related to pregnancy and birth, specifically premature delivery (AL 13.7\%; SP 17.2\%), stillbirth, cephalo-pelvic disproportion, and abortion. Other SAEs included infections (AL 0.6\%; SP 0.8\%), of which there were three cases of severe malaria in the SP group.

\section{Discussion}

WHO treatment guidelines exclude artemisinin compounds for use in the first trimester of pregnancy unless there is no alternative, or the mother's life is at stake $[6,7]$. Preclinical data have raised concerns for ACT exposure in early pregnancy $[7,12,13]$, and yet, despite an unprecedented roll out of ACT, there are only 125 reported cases of human first trimester exposure to artemisinins, albeit with no adverse outcomes [7], a number insufficient to be reassuring regarding safety $[7,23,24]$. This report is based on maternal and birth outcomes in the largest series of prospectively followed ACT-exposed pregnancies, in which there were 495 women in the $\mathrm{AL}$ exposure group, and 156 were exposed during the first

Table 9 Common* adverse events by exposure group

\begin{tabular}{|c|c|c|}
\hline MedDRA Primary System Organ Class: MedDRA Preferred Term & $\begin{array}{c}\text { Artemether-lumefantrine } \\
\mathrm{N}=495 \\
\mathrm{n}(\%)\end{array}$ & $\begin{array}{c}\text { Sulphadoxine-pyrimethamine } \\
\mathrm{N}=506 \\
\mathrm{n}(\%)\end{array}$ \\
\hline Total number of patients with any adverse events & $171(34.5)$ & $186(36.8)$ \\
\hline Blood and lymphatic system disorders: & $7(1.4)$ & $16(3.4)$ \\
\hline Anaemia & $7(1.4)$ & $15(3.2)$ \\
\hline Infections and infestations: & $61(12.3)$ & $66(13.0)$ \\
\hline Malaria & $17(3.4)$ & $34(6.7)$ \\
\hline Syphilis & $24(4.8)$ & $20(4.0)$ \\
\hline Respiratory tract infection & $9(1.8)$ & $5(1.0)$ \\
\hline Urinary tract infection & $5(1.0)$ & $5(1.0)$ \\
\hline Nervous system disorders: & $1(0.2)$ & $8(1.6)$ \\
\hline Headache & $1(0.2)$ & $6(1.2)$ \\
\hline Pregnancy, puerperium, and perinatal conditions: & $108(21.8)$ & $120(23.7)$ \\
\hline Premature baby & $69(13.9)$ & $87(17.2)$ \\
\hline Stillbirth & $9(1.8)$ & $13(2.6)$ \\
\hline Cephalo-pelvic disproportion & $11(2.2)$ & $6(1.2)$ \\
\hline Abortion spontaneous & $6(1.2)$ & $5(1.0)$ \\
\hline
\end{tabular}

Enrolled population: pregnant women who gave informed consent.

MedDRA $=$ medical dictionary for regulatory activities

A pregnant woman with multiple occurrences of an adverse event is counted only once in the corresponding adverse event category.

*Preferred terms occurring in at least $1 \%$ of women in either exposure group are presented along with the corresponding primary system organ class. 
trimester. Outcomes were compared against SP, the most widely used anti-malarial agent administered during pregnancy. Furthermore, a prolonged follow up of infants permitted a thorough investigation of their development following anti-malarial exposure in utero.

The observed rate of perinatal mortality was $4.2 \%$ in the AL group and $5.0 \%$ in the SP group, which is comparable with other data from malaria endemic areas [25-27]. There were no differences between groups with regard to neonatal mortality, maternal mortality, rates of stillbirth, low birth weight, and infant neurological development. Preterm delivery using reported LMP dates (which are notoriously unreliable) was slightly more common in the SP group (17.4\%; AL group $14.1 \%)$, but the majority of infants had birth weights consistent with full-term delivery. Anti-malarial treatment was reportedly well-tolerated. Overall, $22 \%$ of 326 women with a reported test result (i.e. approximately $7 \%$ of the women in each exposure group) had an HIVpositive test. The overall profiles for AEs and SAEs were unremarkable: besides pregnancy complications, most of the commonly reported AEs and SAEs were due to infections, which were also responsible for the majority of maternal deaths.

Women with first trimester AL exposures did not have a greater perinatal mortality rate compared with SP exposure. Infant neurodevelopmental assessments were also similar, irrespective of drug exposure in first trimester. However, there were seven abortions in 159 foetuses exposed to AL in their first trimester, and no abortions in 135 foetuses exposed to SP and/or quinine in their first trimester. In four AL-exposed abortions, the women had risk factors for abortion: two women had three malaria episodes within the first trimester, one woman had syphilis diagnosed 1 week post-AL exposure, and one woman was given salbutamol for threatened abortion concomitantly with AL therapy for malaria. Furthermore, there was no clear relationship between the time at which AL exposure occurred and the occurrence of abortion; except in one case, the abortion occurred long after anti-malarial drug ingestion. Women were mainly enrolled after their first trimester and, therefore, this study could not determine the potential number of abortions that occurred during the first trimester. This may explain the lower abortion rate observed, compared with the $12-16 \%$ spontaneous abortion rate documented [28,29]. It is difficult to draw any definite conclusions from the data, but further monitoring of first trimester exposures to $\mathrm{AL}$ is warranted.

The frequency of birth defects was low and the SAC did not consider that any reported defects (excluding the cases of trisomy) could be described as major. The most frequent finding was umbilical hernia (AL 4.7\%;
SP 2.7\%) and all cases had resolved within 12 months. Umbilical hernia has been reported in rats exposed to artemisinins during gestation [30,31]. It is commonly observed in African infants (17\%-23\%) [21,22], is not generally considered as a "malformation" and the frequency reported here was less than previously documented $[21,22]$. Polydactyly, another reported malformation, is also commonly found in African infants $[32,33]$. Although reasons for the low incidence of major malformations in this study remain unclear, it is unlikely that major malformations (as described by van Regemorter, [34]) would have been missed. Cardiac defects were not detected as cardiac auscultation and/or echocardiograms were not routinely performed, and autopsies were not carried out on deceased infants.

With new data on more than 300 women exposed to AL (referring to index episodes) during the second and third trimester, this study substantially adds to data on the safety of artemisinins in the later stages of pregnancy in African women $[35,36]$, confirming previous findings that AL exposure during this period is well tolerated and has no adverse outcomes for the mother or her exposed foetus.

The study had both strengths and limitations. Firstly, it was undertaken in the context of care provided at antenatal clinics in Zambia, and represents the demographic, infectious disease, and drug exposure profile of pregnant women coming for routine care. The acquisition of drug safety data in pregnancy via clinical trials is associated with various difficulties, risks and costs [37]. Regulatory authorities now recommend observational prospective designs for detecting drug exposure risks or generating margins of reassurance regarding lack of drug exposure risk during pregnancy $[38,39]$. This study followed these recommendations. The majority of women ( $>87 \%$ AL group) had received IPT with SP prior to enrolment or thereafter (only 51 women were exposed to $\mathrm{AL}$ alone), thereby protecting the women from malaria, but also confounding the evaluation of $\mathrm{AL}$ exposure. The index episode was unconfirmed by microscopy or rapid diagnostic test in most $(85 \%)$ participants, which is normal clinical practice at the level of health centres in Zambia where the study was carried out, and it is likely that some of the women exposed to AL and SP may have had other febrile illnesses. This does not change the validity of the information collected, but prevents an analysis of whether the presence of malaria parasites (to which the artemisinins preferentially bind) changed any risk.

Gestational age was assessed by midwives either via LMP (the primary method indicated in the protocol) or through use of the Dubowitz test. The Dubowitz test has been shown to be a reliable method for assessment of gestational age in African neonates [40]. However, 
although all of the investigators received the same type and frequency of training from the same trainers to allow uniform standardized assessments, these results need to be interpreted with some caution as the neonatal assessments were conducted over a long duration of time at multiple sites.

A low incidence of major birth defects could either reflect a lower risk or weaknesses in identifying these risks [41]. On balance, however, as both groups were prospectively monitored without knowing the outcome, the safety data obtained reflect the unbiased outcomes of pregnancies exposed to multiple infections and multiple drugs, including anti-malarials, rather than the consequences of a single well-defined treatment for a single infectious episode.

\section{Conclusions}

With increasing resistance to SP, establishing the margin of safety of ACT in pregnancy is critical. Results from this cohort study confirm that exposure to AL during later pregnancy is not associated with increased safety risks in terms of perinatal mortality, malformations, or infant neurodevelopment, but they also suggest that more safety data are required on first trimester exposure to $\mathrm{AL}$ and consequently for $\mathrm{ACT}$ in general.

\section{List of abbreviations used}

ACT: artemisinin-based combination therapy; AE: adverse event; AL: artemether-lumefantrine; CI: confidence intervals; IPT: intermittent preventive treatment; LMP: last menstrual period; SAC: Study Advisory Committee; SAE: serious adverse event; SP: sulphadoxinepyrimethamine; WHO: World Health Organization.

\footnotetext{
Acknowledgements

The Authors would like to sincerely acknowledge the National Malaria Control Programme in Zambia for their unrelenting support during the conduct of this study, and also thank the study participants and local staff, without whom this study would not have been possible. The local staff consisted of:

Choma site: Dr David Chibuye, Lucia Adams, Alice Changuba, Grace Chulu, Zodwa Hamweene, Berriate Hambwalu, Catherine Mabeta, Margaret C. Muchanga, Mary Mudenda, Tisa Muyola, Siphiwe Mwaba, Idah Nyanga, and the Laboratory staff at Choma Hospital and Shampande Clinic. Lusaka site: Dr Anthony Yeta, Happy Chipulu, Christine Tembo, Christine Omara, and laboratory staff from Chipata clinic. Ndola site: Dr Ignace Gashongore, Elizabeth N'gambi, Rachael Simutowe, Lungowe Musonda, Bupe Luyi, Lister Katongo, Margret Kaumba, Charity Chifita, and the Laboratory staff from Chipulukusu and Lubuto clinics.

The authors would also like to thank Professor C Chintu from the University of Zambia (Lusaka, Zambia), and J Lilienthal from DATAMAP GmbH (Freiburg, Germany) for their participation in the Study Advisory Committee, as well as Dr G Chongwe, J Mthetwa, AC Marrast, F Oladiran, N Mulure, O Nwaiwu, G Mani-Caplazi, P Ibarra de Palacios, and K Andriano. This study was co-sponsored by Novartis Pharma and WHO. The sponsors were responsible for data collection and analysis. Statistical analysis was carried out by DATAMAP GmbH (Freiburg, Germany), and the authors particularly thank M Wibberg and T Widmayer. Medical writing assistance was provided by Dr D Brocksmith (Brocksmith Scientific Ltd, UK).
}

\section{Author details}

${ }^{1}$ Tropical Diseases Research Centre, Ndola, Zambia. ${ }^{2}$ District Health Office, Choma, Zambia. ${ }^{3}$ District Health Office, Ndola, Zambia. ${ }^{4}$ District Health Office, Lusaka, Zambia. ${ }^{5}$ Department of Pediatrics and Child Health, University Teaching Hospital, Lusaka, Zambia. ${ }^{6}$ World Health Organization, Geneva, Switzerland. ${ }^{7}$ Novartis Pharma AG, Basel, Switzerland. ${ }^{8}$ UNICEF, Lilongwe, Malawi. ${ }^{9}$ Former Senior Lecturer, Department of Pharmacology and Toxicology, United Medical Schools of Guy's and St Thomas' Hospitals, University of London, London, UK.

\section{Authors' contributions}

The authors of this manuscript were involved in study design, data interpretation, and the writing of the report, or in a combination of these activities. All authors had full access to study data and held equal final responsibility for the decision to submit this report for publication. All authors contributed either to the design of the study or assisted with data interpretation. CM and MV coordinated the study and supervised enrolment and patient follow-up. WW, RS, MV and CM participated in data entry, collection, and analysis of data. All authors participated in the preparation of the manuscript and approved the final version.

\section{Competing interests}

CM, RM, LP, MS, EM, EN, MCh, and FMS received payments to attend meetings related to the study. W, RS, and MCo are all full time employees of Novartis Pharma and WW and MCo hold stock ownership therein. MG is a full time employee of the WHO. For the duration of the study and manuscript preparation period, MV was a full time employee of Novartis Pharma and holds stock ownership therein. For the duration of the study, IR worked as a full-time consultant for the WHO.

Received: 28 May 2010 Accepted: 1 September 2010 Published: 1 September 2010

\section{References}

1. WHO: Malaria During Pregnancy, The Africa Malaria Report 2003.38-43 [http://www.rollbackmalaria.org/amd2003/amr2003/pdf/amr2003.pdf].

2. Steketee RW, Nahlen BL, Parise ME, Menendez C: The burden of malaria in pregnancy in malaria-endemic areas. Am J Trop Med Hyg 2001, 64(1-2 Suppl):28-35.

3. Desai M, ter Kuile FO, Nosten F, McGready R, Asamoa K, Brabin B, Newman RD: Epidemiology and burden of malaria in pregnancy. Lancet Infect Dis 2007, 7:93-104.

4. Shulman CE, Dorman EK, Cutts F, Kawuondo K, Bulmer JN, Peshu N, Marsh K: Intermittent sulphadoxine-pyrimethamine to prevent severe anaemia secondary to malaria in pregnancy: a randomised placebocontrolled trial. Lancet 1999, 353:632-636.

5. Mbaye A, Richardson K, Balajo B, Dunyo S, Shulman C, Milligan P, Greenwood B, Walraven G: A randomized, placebo-controlled trial of intermittent preventive treatment with sulphadoxine-pyrimethamine in Gambian multigravidae. Trop Med Int Health 2006, 11:992-1002.

6. WHO: Guidelines for the treatment of malaria 2010 [http://www.who.int/ malaria/publications/atoz/9789241547925/en/index.html].

7. WHO: Assessment of the safety of artemisinin compounds in pregnancy 2007 [http://apps.who.int/tdr/svc/publications/tdr-research-publications/ artemisinin-compounds-pregnancy]

8. McGready R, Cho T, Keo NK, Thwai KL, Villegas L, Looareesuwan S, White NJ, Nosten F: Artemisinin antimalarials in pregnancy: a prospective treatment study of 539 episodes of multidrug-resistant Plasmodium falciparum. Clin Infect Dis 2001, 33:2009-2016.

9. Li GQ, Guo XB, Fu LC, Jian HX, Wang XH: Clinical trials of artemisinin and its derivatives in the treatment of malaria in China. Trans $R$ Soc Trop Med Hyg 1994, 88(Suppl 1):S5-S6.

10. Wang TY: Follow-up observation on the therapeutic effects and remote reactions of artemisinin (Qinghaosu) and artemether in treating malaria in pregnant women. J Trad Chinese Med 1989, 9:28-30.

11. McGready R, Tan SO, Ashley EA, Pimanpanarak M, Viladpai-Nguen J, Phaiphun L, Wüstefeld K, Barends M, Laochan N, Keereecharoen L, Lindegardh N, Singhasivanon P, White NJ, Nosten F: A randomised controlled trial of artemether-lumefantrine versus artesunate for uncomplicated Plasmodium falciparum treatment in pregnancy. PLOS Med 2008, 5:e253. 
12. White TEK, Bushdid PB, Ritter S, Laffan SB, Clark RL: Artesunate-induced depletion of embryonic erythroblasts precedes embryolethality and teratogenicity in vivo. Birth Defects Res 2006, 77:413-429.

13. Clark RL, Kumemura M, Makori, Nakata Y, Bernard F, Harrell A, White TEK, Arima A: Artesunate: developmental toxicity in monkeys. Birth Defects Res 2006, 76:329, [Abstract].

14. Sipilanyambe N, Simon JL, Chanda P, Olumese P, Snow RW, Hamer DH: From chloroquine to artemether-lumefantrine: the process of drug policy change in Zambia. Malar J 2008, 7:25.

15. Munjanja SP, Masona D: Zimbabwean birth weight for gestation standards. Central African J Med 1990, 36:144-147.

16. Dubowitz LMS, Dubowitz V, Goldberg C: Clinical assessment of gestational age in the newborn infant. J Pediatr 1970, 77:1-10.

17. Haataja L, McGready R, Arunjerdja R, Simpson JE, Mercuri E, Nosten F, Dubowitz $L$ : A new approach for neurological evaluation of infants in resource-poor settings. Ann Trop Paediatr 2002, 22:355-368.

18. Rubin DE: Multiple imputation after 18+ years. J Am Statist Assoc 1996, 19:473-489.

19. D'Agostino RB: Propensity score methods for bias reduction in the comparison of a treatment to a non-randomized control group. Statist Med 1998, 17:2267-2281.

20. Schulz KF, Cates W Jr, O'Mara PR: Pregnancy loss, infant death and suffering: legacy of syphilis and gonorrhoea in Africa. Genitourin Med 1987, 63:322.

21. Meier DE, OlaOlorun DA, Omodele RA, Nkor SK, Tarpley JL: Incidence of umbilical hernia in African children: redefinition of "normal" and reevaluation of indications for repair. World J Surg 2001, 25:645-648.

22. Ebomoyi E, Parakoyi DB, Omonisi MK: Nutritional status and umbilical hernia in Nigerian school children of different ethnic groups. J Natl Med Assoc 1991, 83:905-908.

23. Dellicour S, Hall S, Chandramohan D, Greenwood B: The safety of artemisinins during pregnancy: a pressing question. Malar J 2007, 6:15.

24. Dellicour S, ter Kuile FO, Stergachis A: Pregnancy exposure registries for assessing antimalarial drug safety in pregnancy in malaria-endemic countries. PLoS Med 2008, 5:e187.

25. McDermott JM, Wirima JJ, Steketee RW, Breman JG, Heymann DL: The effect of placental malaria infection on perinatal mortality in rural Malawi. Am J Trop Med Hyg 1996, 55:61-65.

26. Kumala T, Vaahtera M, Ndekha M, Koivisto AM, Cullinan T, Salin ML, Ashorn P: The importance of preterm births for peri- and neonatal mortality in rural Malawi. Paediatr Perinatal Epidemiol 2000, 14:219-226.

27. van Geertruyden JP, Thomas F, Erhart A, D'Alessandro U: The contribution of malaria in pregnancy to perinatal mortality. Am J Trop Med Hyg 2004, 71:35-40.

28. Everett C: Incidence and outcome of bleeding before the 20th week of pregnancy: prospective study from general practice. BMJ 1997, 315:32-34.

29. Mills $\mathrm{J}$, Simpson $\mathrm{L}$, Driscoll SG, Jovanovic-Peterson $L$, Van Allen $M$, Aarons JH, Metzger B, Bieber FR, Knopp RH, Holmes LB: Incidence of spontaneous abortion among normal women and insulin-dependent diabetic women whose pregnancies were identified within 21 days of conception. NEJM 1988, 319:1617-1623.

30. China Cooperative Research Group on Qinghaosu and its Derivatives as Anti-malarials: Studies on the toxicity of Qinghaosu and its derivatives. J Tradit Chin Med 1982, 2:31-36.

31. Clarke RL: Embryotoxicity of the artemisinin antimalarials and potential consequences for use in women in the first trimester. Reprod Toxicol 2009.

32. Simpkiss $M$, Lowe $A$ : Congenital abnormalities in the African newborn. Arch Child Dis 1961, 404-406.

33. Kromberg JG, Jenkins T: Common birth defects in South African Blacks. $S$ Afr Med J 1982, 16:599-602.

34. van Regemorter N, Dodion J, Druart C, Hayez F, Vamos E, FlamentDurand J, Perlmutter-Cremer N, Rodesch F: Congenital malformations in 10,000 consecutive births in a university hospital: need for genetic counseling and prenatal diagnosis. J Pediatr 1984, 104:386-390.

35. Adam I, Ali DM, Abdalla MA: Artesunate plus sulfadoxine-pyrimethamine in the treatment of uncomplicated Plasmodium falciparum malaria during pregnancy in eastern Sudan. Trans R Soc Trop Med Hyg 2006 100:632-635.
36. Deen $J$, von Seidlein $L$, Pinder M, Walraven GE, Greenwood BM: The safety of the combination artesunate and pyrimethamine-sulfadoxine given during pregnancy. Trans R Soc Trop Med Hyg 2001, 95:424-428.

37. Ward SA, Sevene EJP, Hastings IM, Nosten F, McGready R: Antimalarial drugs and pregnancy: safety, pharmacokinetics, and pharmacovigilance. Lancet Infect Dis 2007, 7:136-144.

38. U.S Food and Drug Administration Center for Drug Evaluation and Research: Guidance for industry: establishing pregnancy exposure registries. 2002 [http://www.fda.gov/downloads/Drugs/ GuidanceComplianceRegulatorylnformation/Guidance/ucm071639.pdf].

39. European Medicines Agency: Guideline on exposure to medicinal products during pregnancy: need for post-authorisation data. 2005 [http://www.emea.europa.eu/pdfs/human/phwwp/31366605en.pdf]

40. Dawodu $A H$, Effiong CE: Assessment of gestational age in full term and preterm African newborn infants. Nig J Pediat 1977, 4:1-5.

41. Sayed AR, Bourne D, Pattinson R, Nixon J, Henderson B: Decline in the prevalence of neural tube defects following folic acid fortification and its cost-benefit in South Africa. Birth Defects Res 2008, 82:211-216.

doi:10.1186/1475-2875-9-249

Cite this article as: Manyando et al:: Safety of artemether-lumefantrine in pregnant women with malaria: results of a prospective cohort study in Zambia. Malaria Journal 2010 9:249.

\section{Submit your next manuscript to BioMed Central and take full advantage of:}

- Convenient online submission

- Thorough peer review

- No space constraints or color figure charges

- Immediate publication on acceptance

- Inclusion in PubMed, CAS, Scopus and Google Scholar

- Research which is freely available for redistribution

Submit your manuscript at www.biomedcentral.com/submit
C Biomed Central 